\title{
Problem of Obstetrical Evacuations: About 630 Cases Collected at the Maternity of Bouake University Hospital
}

\author{
Lydie Estelle Djanhan', Jean Marc Dia2*, Messou Michelle Menin', Yaya Samaké1, \\ Claussen M'broh', Kouadio Narcisse Kouadio', Kouamé Privat Kouakou1, Yacouba Doumbia1 \\ ${ }^{1}$ Department of Gynecology and Obstetrics, University and Hospital Center of Bouaké (CHUB), Bouaké, Côte d'Ivoire \\ ${ }^{2}$ Department of Gynecology and Obstetrics, University and Hospital Center of Treichville (CHUT), Abidjan, Côte d'Ivoire \\ Email: *jmlaminedia@yahoo.fr
}

How to cite this paper: Djanhan, L.E., Dia, J.M., Menin, M.M., Samaké, Y., M’broh, C., Kouadio, K.N., Kouakou, K.P. and Doumbia, Y. (2018) Problem of Obstetrical Evacuations: About 630 Cases Collected at the Maternity of Bouake University Hospital. Open Journal of Obstetrics and $G y$ necology, 8, 253-262.

https://doi.org/10.4236/ojog.2018.83027

Received: December 5, 2017

Accepted: March 27, 2018

Published: March 30, 2018

Copyright $\odot 2018$ by authors and Scientific Research Publishing Inc. This work is licensed under the Creative Commons Attribution International License (CC BY 4.0).

http://creativecommons.org/licenses/by/4.0/ (c) (i) Open Access

\begin{abstract}
Objective: To improve the care of evacuees at the maternity of the University Hospital Center of Bouake (CHUB). Methodology: This is a cross-sectional and descriptive study over a period of three months that covered 630 cases collected at the Maternity of the university Hospital of Bouaké. Results: Obstetric evacuation accounted for $42.5 \%$ of admissions to the delivery room. Patients under 20 years and over 34 years of age respectively represented $21 \%$ and $13.5 \%$ of the total. $62.7 \%$ of evacuees were not educated and $84.9 \%$ had low economic level. Nulliparous and multiparous women accounted for $54.9 \%$ of the patients and $88 \%$ had mean prenatal follow up. The evacuations were decided by midwives $(91.3 \%)$, without previous adapted treatment $(79.4 \%)$, with a badly filled evacuation card (49.7\%) and no partograph. The taxi was the most used means of transportation (75.2\%) and most evacuees took less than one hour to access the referral center (61.4\%). The reasons for evacuation are mainly dominated by mechanical obstructions (34.8\%); on admission the evacuees with no real reference reason were 243 (38.6\%) and the diagnosis was inconsistent in $43 \%$ of cases. The majority of evacuated women delivered vaginally (69.4\%). Most newborns had a satisfactory state at the 5th minute of life $(79.4 \%)$ and we noted 54 cases $(08.3 \%)$ of neonatal deaths. $7.8 \%$ of evacuees had a complication dominated by postpartum anemia (51.1\%); we had lamented 17 cases $(2.7 \%)$ of maternal deaths among evacuees, attributable to delivery haemorrhage (47.1\%) and eclampsia (23.5\%). Conclusion: A better organization of the reference and an equipment of the peripheral health structures would improve the prognosis of the evacuees.
\end{abstract}

\section{Keywords}

Obstetric Emergencies, Evacuations, Reference, Maternal Mortality 


\section{Introduction}

Maternal mortality is a major public health problem around the world and its assessment shows high numbers, especially in sub-Saharan Africa [1].

According to Adamson Peter [2], 15\% of pregnancies don't benefit from modern obstetric care, and to reduce maternal mortality, they should be identified and managed as soon as possible.

For this, an important role is given to the transfer of women to specialized centers, hence the interest of evacuation.

Fournier estimated that two years after the implementation of the referral/evacuation system, very positive effects are obtained with the improvement of basic emergency obstetric and neonatal care coverage, with a decrease in mortality [3].

Several studies on the system of obstetric evacuation have been made in Africa. In Cote d'Ivoire the works on this theme are not recent. We conducted this study whose objective was to carry out a comprehensive evaluation of obstetric evacuation in a reference health center. In this case the CHUB was a referral center for patients from different cities in emergency. This was in order to improve the care of evacuees in the gynecology-obstetrics department.

\section{Methodology}

This was a transversal and descriptive study conducted over a three-month period from February 1, 2006 to April 30, 2016 on patients discharged from peripheral centers in our department for obstetric emergency.

We included in the study all parturients and recent births (48 hours postpartum) with an evacuation record. Were excluded from the study, parturients and recent births without evacuation records and those with incomplete records. Thus 630 patient met our inclusion criteria,

We studied the following parameters: the frequency of the evacuations, the socio-demographic and clinical characteristics of the evacuees, the data of the evacuation form, the evacuation conditions, the maternal-fetal prognosis.

Data collection was done using a survey questionnaire, delivery records and obstetric emergencies, evacuees medical records and evacuation support, which is the evacuation record.

The data were analyzed using Epi Info 7, Excel and Word software.

\section{Framework of the study}

The University Hospital of Bouake is the only center of reference of the second largest city of the Ivory Coast. It covers a population of 3.5 million.

The patients evacuated in our department come from three different zones. Those coming from:

- the city of Bouakétravel less than 5 kilometers.

- the region of Gbèkè (in the surrounding areas of Bouaké) travel between 5 75 kilometers.

- the other regions than the region of Gbèkè travel more than 75 kilometers. 
In our department, we practice an average of 6000 deliveries a year and 13,000 consultations including 9000 prenatal consultations

\section{Results}

\subsection{The Frequency of Obstetric Evacuation}

During the study period we recorded 1484 obstetric emergencies, of which 1101 were evacuees from the peripheral centers, a frequency of $74.2 \%$.

Of these 1101 evacuees, 630 met our inclusion criteria, a frequency of $42.5 \%$.

\subsection{Socio-Demographic Characteristics}

In $84.9 \%$ the socio-economic level was judged low (Table 1 ).

Table 1. Distribution of patients according to sociodemographic data $(\mathrm{N}=630)$.

\begin{tabular}{|c|c|c|}
\hline Socio-demographic characteristics & population & Percentage (\%) \\
\hline \multicolumn{3}{|l|}{ Age (years) } \\
\hline$<20$ & 132 & 21 \\
\hline $20-24$ & 156 & 24.8 \\
\hline $25-29$ & 138 & 21.9 \\
\hline $30-34$ & 119 & 18.9 \\
\hline$>34$ & 85 & 13.5 \\
\hline \multicolumn{3}{|l|}{ Parity } \\
\hline nulliparous & 217 & 34.4 \\
\hline pauciparous & 284 & 45.1 \\
\hline multiparous & 129 & 20.5 \\
\hline \multicolumn{3}{|l|}{ economic level* } \\
\hline low & 535 & 84,9 \\
\hline mean & 95 & 15,1 \\
\hline high & 00 & 00 \\
\hline \multicolumn{3}{|l|}{ Level of education } \\
\hline None & 395 & 62.7 \\
\hline Primary & 120 & 19 \\
\hline Secondary & 83 & 13.2 \\
\hline Superior & 32 & 5.1 \\
\hline \multicolumn{3}{|l|}{ Quality of prenatal follow-up** } \\
\hline Good & 00 & 00 \\
\hline Mean & 554 & 88 \\
\hline bad & 76 & 12 \\
\hline
\end{tabular}

*The economic level was deemed low when the monthly income of the couple was below the minimum wage in Côte d'Ivoire (100 euros). And it was estimated average when income was less than 200 euros (less than the double of the minimum wage). ${ }^{*}$ Prenatal follow-up was considered good when the recommended number of prenatal consultations (PCN) and prenatal check up (PCU) were actually performed. It was average when PCN or PCU were not completely done. And it was considered bad when no PCN and no PCU were done. $88 \%$ of the patients had mean prenatal follow up. 
The average age was 25.93 years, with extremes of 14 years and 48 years. $\mathrm{Pa}$ tients under 20 years and over 34 years of age respectively represented $21 \%$ and $13.5 \%$ of the total.

$62.7 \%$ of evacuees were not educated and $84.9 \%$ had low economic level.

Nulliparous and multiparous women accounted for $54.9 \%$ of the patients.

\subsection{The Evacuation Parameters}

Urban health centers evacuated $75.2 \%$ of patients; the evacuees came from the city of Bouaké in $69.8 \%$ of the cases. Most of the evacuations were done by midwives $(91.3 \%)$.

The evacuation form was badly filled in $49.70 \%$ of cases. No partograph was associated with the evacuation record for all evacuees (Table 2).

$79.4 \%$ of patients did not receive care prior to evacuation.

The taxi was the most used means of transport (75.2\%). It should be noted that no health worker accompanied the evacuees.

The average time spent in our series was $1 \mathrm{~h} 21$ minutes with a minimum of 7 minutes and a maximum of 18.5 hours.

The evacuees took more than 1 hour to access the CHUB maternity in $38.6 \%$ of cases.

Table 2. Distribution of patients according to evacuation parameters $(\mathrm{N}=630)$.

\begin{tabular}{|c|c|c|}
\hline parameters & population & Percentage (\%) \\
\hline \multicolumn{3}{|l|}{ Origin* } \\
\hline city of Bouake & 440 & 69.8 \\
\hline Region of Gbèkè & 119 & 18.9 \\
\hline Other regions & 71 & 11.3 \\
\hline \multicolumn{3}{|l|}{ Origin Structure } \\
\hline Urban Health Centers & 477 & 75.7 \\
\hline Rural Health Centers & 71 & 11.3 \\
\hline General hospitals & 64 & 10.1 \\
\hline Private clinics & 18 & 2.9 \\
\hline \multicolumn{3}{|c|}{ Officer in charge of the evacuation } \\
\hline midwives & 590 & 93.6 \\
\hline nurses & 34 & 05.4 \\
\hline Doctors & 06 & 01 \\
\hline \multicolumn{3}{|l|}{ Evacuation form } \\
\hline Well completed & 317 & 50.3 \\
\hline Badly completed & 313 & 49.7 \\
\hline \multicolumn{3}{|l|}{ Care before evacuation } \\
\hline Care adapted to the motive & 130 & 20.6 \\
\hline No & 500 & 79.4 \\
\hline
\end{tabular}




\section{Continued}

\begin{tabular}{ccc}
\hline Means of evacuation & & \\
Taxis & 482 & 76.5 \\
Ambulances & 139 & 22.1 \\
Personal vehicles & 05 & 0.8 \\
Motorbikes & 04 & 0.6 \\
Journey duration (hour) & & \\
$<1$ & 387 & 61.4 \\
$1-2$ & 122 & 19.4 \\
$2-4$ & 76 & 12.1 \\
$>4$ & 45 & 7.1 \\
\hline
\end{tabular}

\section{Clinical Data}

\subsection{The Diagnosis Retained on Admission}

The evacuees who did not present any real motive of reference accounted for $38.6 \%$; mechanical dystocia was used as a diagnosis in $26.3 \%$ of cases (Table 3 ).

In $43 \%$ of cases the diagnosis was not consistent with the motive for the evacuation.

\subsection{The Mode of Delivery and the Condition of the Newborn}

$69.4 \%$ of evacuees delivered vaginally.

$84.8 \%$ of newborns had apgar scores $\geq 7$ and $08.3 \%$ of newborns died (Table $4)$.

\subsection{The Maternal Prognosis}

In $89.5 \%$ of cases the evolution was satisfactory.

We noted 17 maternal deaths in the evacuees out of 23 maternal deaths recorded in the service during the study period, including $52.9 \%$ by post-partum hemorrhage (Table 5).

\section{Discussion}

\subsection{The Frequency of Obstetric Evacuation}

In our study, the frequency of obstretic evacuation was $42.5 \%$.

The frequencies vary from one study to another. This is due to the way patients are recruited, the criteria for inclusion, the importance of the center and its location area.

This high rate reported in our series could be explained by the fact that our hospital (study center) is the only reference university and hospital center located in province; It is in the second largest city of Cote d'Ivoire and covers a radius of about $200 \mathrm{~km}$. 
Table 3. Distribution of patients according to diagnosis on admission.

\begin{tabular}{ccc}
\hline diagnosis & population & Percentage (\%) \\
\hline Diagnosis retained & 243 & 38.6 \\
- Evacuees without problems & 166 & 26.3 \\
- Mechanical dystocia & 62 & 09.8 \\
- acute foetal suffering & 44 & 07 \\
- high blood pressure and complications & 29 & 04.6 \\
- post partum Hemorrhage & 24 & 03.8 \\
- third term pregnancy Hemorrhagia & 62 & 09.8 \\
- Other & 630 & 100 \\
- total & & \\
Concordant diagnosis & 359 & 57 \\
Yes & 271 & 43 \\
No & 630 & 100 \\
\hline
\end{tabular}

Table 4. Distribution of patients according to the mode of delivery and the condition of the newborn.

\begin{tabular}{|c|c|c|}
\hline Delivery conditions & population & percentage (\%) \\
\hline \multicolumn{3}{|l|}{ Mode of delivery } \\
\hline Vaginal route & 437 & 69.4 \\
\hline caesarean & 177 & 28.1 \\
\hline laparotomy & 16 & 02.5 \\
\hline Total & 630 & 100 \\
\hline \multicolumn{3}{|l|}{ Apgarscore } \\
\hline$\geq 7$ & 551 & 84.8 \\
\hline 0 & 54 & 08.3 \\
\hline $1-6$ & 45 & 06.9 \\
\hline total & 650 & 100 \\
\hline \multicolumn{3}{|l|}{ condition of the newborn } \\
\hline satisfactory & 516 & 79,4 \\
\hline referred in neonatalogy & 80 & 12.3 \\
\hline deceased & 54 & 08.3 \\
\hline total & 650 & 100 \\
\hline
\end{tabular}


Table 5. Distribution of patients according to maternal prognosis.

\begin{tabular}{ccc}
\hline prognosis & population & percentage (\%) \\
Prognosis & 564 & 89.5 \\
Satisfactory evolution & 49 & 07.8 \\
Complications & 17 & 02.6 \\
deaths & 630 & 100 \\
total & & \\
causes of death & 09 & 52.9 \\
- post partum Hemorrhage & 04 & 23.5 \\
- Eclampsia & 02 & $11 ; 7$ \\
- acute pulmonary edema & 01 & 05.9 \\
- Brain embolism & 01 & 05.9 \\
- severe malaria & 17 & 100 \\
\hline
\end{tabular}

\subsection{Sociodemographic Profile}

From the analysis of our results, the patients studied had many risk factors that could have been detected earlier to prevent certain complications.

The first factor identified is related to age. We have indeed noted a high rate of patient at the extreme ages of their fertility: $21 \%$ of adolescent girls and $13.5 \%$ of patients over 34 years. These are periods of high risk of complications in obstetrics. These situations are common in our regions because of socio-cultural habits. Indeed the area of Bouaké is a semi-urban area where early marriages are common in the rural part. Moreover, in these rural areas the notion of family planning is hardly accepted, explaining that women over 34 continue to have children. Several authors have found the same thing as us by reporting high rates of adolescent girls in their study [4] [5] [6] [7] [8].

The second risk factor found was parity. The majority of our patients were either nulliparous (34.4\%) or multiparous (20.5\%), who are 2 groups exposed to obstetric complications.

The third risk factor identified was the poor socio-economic conditions of the majority of our patients: $84.9 \%$ of patients had a low economic level, rates copied to those reported by Traore D. [7] and Macalou B. [9] and Cisse [10]; and 62.7\% were not educated.

These patients were thus exposed to the ignorance and financial difficulties of management of the pregnancy.

The last risk factor identified was poor pregnancy monitoring. Indeed, no patient had a good prenatal follow-up.

Given these different risk factors, it is therefore important to provide a high-performance evacuation system to reduce maternal mortality as advocated by Adamson Peter [2] 


\subsection{The Evacuation Parameters}

\section{-health worker responsible for the evacuation}

In our series $91.3 \%$ of the patients were evacuated by midwives, compared to $6 \%$ by doctors; several authors found such high rates of evacuation by midwives [4] [7] [8] [11]. On the other hand, Berthe D [12] in Mali noted in his study $34.4 \%$ evacuations made by doctors compared to $24.8 \%$ by midwives.

The high rate of evacuation performed by midwives testifies the fact that among medical staff they are the most numerous in the obstetrical health structures in Cote d'Ivoire ( 1 midwife for 2000 inhabitants compared to 1 doctor for 9000 inhabitants).

The retraining, upgrading and awareness of some midwives could help prevent abusive evacuations and delays in evacuation.

\section{-Means of transport}

$74.6 \%$ of the patients were evacuated by taxi in our work; Sépou [11] reported a rate of $68.6 \%$ whereas the ambulance was the most used means of evacuation in the series of Thiam [5], Thera [13], Guindo [14].

The disadvantage of the transfer made in non-medical conditions is the aggravation of the health conditions of the patients.

It is therefore necessary that interventions aiming at improving the transport of women with complications be divided into two categories: those aiming at improving the transport of women from their community to the health center and those aiming at improving transport between two health centers of different levels [15].

-The Admission delay

The average time taken by patients to access the reference center in our series was $1 \mathrm{~h} 21$ minutes

The high admission time was due to road conditions, lack of vehicle and distance. It was also due to the lack of financial means, the non-acceptance of "the eventual cesarean section". These reasons sent the parents home before going to the referral center.

The lack of medical transport and the high admission delay help to delay the referral of patients and this contributes to aggravate the fetomaternal prognosis

\subsection{Clinical Data}

In $43 \%$ of the cases the diagnosis was not consistent and $38.6 \%$ of the evacuees had not presented a real reason for referral;

This evacuation would be triggered by a superficial diagnosis related to the quality of the health worker and / or the quality of the technical platform; The delivery could have been done in the first contact health center and avoid the cost of additional transportation.

Thera [13] noted in his study that $92.2 \%$ of references were adequate, $78.3 \%$ justified and $72.2 \%$ appropriate.

During the study period, we recorded 23 cases of maternal deaths including 17 
discharged patients (74\%) meeting our inclusion criteria; results comparable to those reported by Cisse ML: [10] and Tshalu-Aguemon [16].

These patients arrived in our service in very precarious states due to the lack of adequate care before their transfer, the lack of adequate means of evacuation, the admission time delayed. Obstetric evacuation remains a negative factor in the maternal-fetal prognosis in our regions and makes access to effective care one of the solutions to the drama of maternal mortality.

\section{Conclusions}

This study enabled us to highlight that the evacuations were poorly organized. The patients were poorly prepared; they were evacuated in mediocre conditions worsening prognosis of mothers and newborns.

There is therefore a need to continue strengthening the capacity of peripheral maternity hospitals in terms of material and human resources to make them the minimum care facilities for obstetric emergencies; and to ensure the continuous training and retraining of health workers. This would contribute, through the reduction of certain factors aggravating the prognosis of the evacuated patients, to the reduction of maternal mortality which is still very high in our country.

\section{References}

[1] World Health Organization (2004) Maternal Mortality in 2000. Estimates Developed by WHO, UNICEF and UNFPA. WHO, Geneva.

[2] Adamson, P. Le monde est sourd. Le progrès des nations, https://www.unicef.org/french/pon96/pon96fre.pdf

[3] Fournier, P. (2012) Influence des trois retards sur les décès maternels: Revue de 222 cas dans la Région de Kayes (2008-2011). Atelier de restitution du programme de recherche appliquée; Kayes le 30 mars 2012.

[4] Doumbia, Y., Djanhan, Y., Kouakou, P., Djanhan, L. and Kouakou, N. (2007) Pertinence du motif d'évacuation de la parturiente à la formation sanitaire urbaine d'Abobo-sud. Afrique Biomédicale, 12, 23-28.

[5] Thiam, O., Cissé, M.L., Mbaye, M., Niang, M.M., Gueye, M., Diouf, A.A., et al. (2013) Problématique des parturientes évacuées en zone rurale sénégalaise: Exemple du centre hospitalier de Ndioum. Rev.CAMES santévol1, No. 2, décembre: 51-56.

[6] Coulibaly, A. (2006) La référence/évacuation Gynéco-obstétricale au centre de santé de référence de la commune $\mathrm{V}$ du district sanitaire de Bamako. Thèse de Méd. Bamako.

[7] Traore, D. (2010) Problématique du système de référence/évacuation des urgences obstétricales au CS de référence du district sanitaire de Bamako. Thèse de Méd. Bamako.

[8] Mounthaka, M. (2009) Les urgences obstétricales dans le cadre de la référence et contre référence au CS Réf C VI. Thèse Méd. Bamako.

[9] Macalou, B. (2002) Les évacuations sanitaires en obstétrique à l'hôpital régional Fousseyni Daou de Kayes. Thèse Méd. Bamako, №14.

[10] Cissé, M.L. (2010) Bilan des évacuations obstétricales à l’hôpital de Kolda (Sénégal). Médecine d'Afrique Noire, 57, 37-43. 
[11] Sépou, A., Goddot, M., Ngbalé, R., Gaunefet, C.E., Domandé-Modanga, Z., Fandema, E., et al. (2009) Evaluation de la fréquence et les problèmes liés aux évacuations sanitaires versle service de gynécologie obstétrique de l'hôpital communautaire de Bangui. Clinics in Mother and Child Health, 6, 1007-1012.

[12] Berthe, D. (2011) Les évacuations obstétricales à l'hôpital Fousseny Daou de Kayes/à propos de 322 cas. Thèse med. Bamako.

[13] Thera, T., Traoré, Y., Kouma, A., Diallo, B., Traoré, Z., Traoré, M., et al. (2015) Problématique dusystème deréférence-contre référence desurgences obstétricales et'implantation des communautés dansle districtde Bamako. MaliMédical Tome, 30, 34-37.

[14] Guindo, S. (2008) Les urgences obstétricales dans le cadre de la référence et la contre référence au service de Gynécologie-Obstétrique à l'hôpital de Sikasso. Thèse med. Bamako.

[15] Doumbia, S. (2010) Les évacuations sanitaires obstétricales. Pronosticmaternelet périnatalaucentrede santé de référence delacommune v. Thése demed, Bamako, 22.

[16] Tshalu-Aguèmon, C., Denakpo, J., Adisso, S., Mampassi, E. and de Souza, J. (2012) Mortalités maternelles et périnatales liées aux références obstétricales à Cotonou, SARANF mai 2012. 